\title{
Negotiating the Web: Legal skills learning in a virtual community
}

\author{
Paul Maharg \\ Glasgow Graduate School of Law
}

\begin{abstract}
'The concept of learning is often, for me and many other educators, too focused on mechanical formalities, on systems of accreditation and assessment, rather than the poetics of learning and creativity.
\end{abstract}

(West, 1996, 211-2)

\section{Introduction: constructivism, interactivity and legal skills}

How best can we use the web for legal learning? This article explores some of the theory and practice behind one approach, namely a constructivist approach to a simulated environment for legal skills learning. ${ }^{1}$ Simulation is one of the strikingly intuitive uses of the web -- Sherry Turkle is one of a number of commentators who have pointed out the potential of the web for identity-change and simulation (Turkle 1997). One of the critical elements of web-based simulations is the manner in which it changes the nature and function of interactivity in learning. 'Interactivity', though, is a term that is capable of quite a number of different interpretations, and since I shall be using it throughout this article, I shall attempt a definition. There are three forms of interactivity: with resources, with peers, and with self.

\section{Interaction with resources}

As literary critics have noted about, for example, the way in which a poem is set out on a page, form affects content and function. The way that a set of resourcebased learning materials is laid out and presented affects the reader's sense of the materials, and the way in which he or she interacts with them.

This is even more the case with web-based materials. 'Shovelware' indiscriminately throwing lecture notes or other materials on to web pages - is well acknowledged now to be a poor use of the medium. The web is built upon a unique connectivity, and gives immediate access to information and knowledge that can be a powerful learning tool. This needs to be harnessed in various ways. How we do this requires that we use imagination and creativity in order to facilitate student learning. As David Dickinson observed, Interactive multimedia has to be more than just software that you click on to bring up a different pop-up or text-menu. 'Interactive' has to mean more than point and click - it should be involving and personal. It all comes down to concepts. A brilliant idea that works interactively ... is a way that makes sense, and that makes [ICT] a more appropriate tool than a book or a video or a set of crayons. (Dickinson, 1995, 144-45)

\footnotetext{
${ }^{1}$ The term 'constructivism' will be defined in more context below.
} 


\section{Interaction with peers}

The web is an ideal medium for collaborative learning. Chat rooms, discussion forums, MOOs, MUDs, web-based games - all these exploit the innate communicative function of the web. But the web does not merely facilitate communication between users: it changes the context under which work can be carried out. Where a learner may in the past have had difficulty in collaborating with peers, particularly at a distance, the web can enable co-operative working. The collaborative context is not merely an option: much online learning is actually enhanced if it is performed collaboratively, rather than by individuals. This has been reported in a number of studies - see, for example, Hiltz et al 2000:

When students are actively involved in collaborative learning online, the outcomes can be equal to or better than those for traditional classes. If, however, individuals in an online environment simply work on posted materials and return individual work, the results are poorer than in traditional classrooms.

\section{Interaction with self}

In this third form of interaction, users reflect upon the learning resources, both content and procedures by which that knowledge can be learned. They conduct a dialogue with the materials, rather than consuming them, or being subsumed by them. The reflection is thus close to what Ronald Barnett called 'critical reflection', and a number of commentators have pointed out that this is essential to learning. Diana Laurillard observed that, however essential this dialogic nature of reflection is, it can occur in a number of ways:

'[f]or learning to take place, the core structure of the conversational framework must remain intact in some form: the dialogue must take place somewhere, the actions must happen somewhere, even if it is all done inside the student's head. (Laurillard, 1993, 105)

Even if the dialogue happens wholly within a student's head, the conversation needs to be stimulated. This means that curiosity needs to be aroused. Schank $\&$ Cleary put this well when they commented that

[b]asic self-interest, if it is allowed to flourish intellectually, can lead to a wide variety of discoveries motivated by curiosity based on internal needs. If we want to allow students to pursue their own interests, we need to provide them with a way to get their questions answered. Many of the teaching architectures are, in fact, specifically designed to bring students to the point that they want to know something. How are we to help them?

Their last question is pertinent to all web-based learning. It is a necessary but not sufficient condition of learning that students' curiosity is aroused in some way or other. Learning, though, can be facilitated through structured interventions, and I would argue that the negotiation of meaning, facilitated through 'teaching architectures' that promote the three forms of reflection above, is one powerful method of so doing.

All three of these forms of interaction are important to the success of online learning. Not all of them need be present, of course, in learners' interactions with the web; but in most interactions, one or other of these forms of negotiated learning over the web will take place. This was particularly true of the following case study of web-based learning in legal skills learning, the Personal Injury Negotiation Project. 


\section{Aims and theoretical background}

Before I describe the aims of the project, some background information about the context of the course is required. The project is part of a professional postgraduate course called the Diploma in Legal Practice, which LLB students in Scotland must complete to be solicitors or advocates. The one-year course is held in the Glasgow Graduate School of Law, which is a joint graduate school between Glasgow and Strathclyde University Law Schools. The Diploma starts with a Foundation Course in Professional Legal Skills, which follows a cognitivist model of skills learning (tell-show-do) and which aims to introduce students quickly to five of the six skill sets stipulated by the Law Society of Scotland in their new skills-based curriculum for the subject, namely legal writing, drafting, interviewing, negotiation and advocacy (legal research is dealt with later on in the Diploma). Thus, in the negotiation skills unit, students were given a lecture on the skills and the context of negotiation. They were then given a multimedia simulation of a negotiation session (on CD, also accessible from a streaming server on our intranet). They then practised the skills in three separate workshops, each with a more complex scenario than the former.

The aim of the Personal Injury (PI) project within the Diploma is to advance students' learning of legal negotiation skills from a fairly bounded domain of learning on the Foundation Course to a much more open field domain, where negotiation is integrated with writing skills, problem-solving, factual research, legal research and much else. Students are required to represent their client and to achieve the best possible negotiated settlement for him, given the scenario within which they work.

The assessment criteria for the project are similarly broad. Students are informed that they will be assessed on four areas, for which they need to provide evidence:

1. fact-finding

2. legal research

3. formation of negotiation strategy

4. performance of strategy

If the firms are to negotiate face to face, they are allowed to do so only once, and the encounter has to be audio- or videotaped. They are informed that there are three levels of achievement: not yet competent, competent, and merit. Finally, each student is required to write a 1,000 word reflective report on the experience of working on the project, what they learned from it, what they would do differently next time, and how the project could be improved.

These aims and assessment criteria are fairly wide ranging. There are two points to be made about them. First, the aims represent the creation of a constructivist environment. Second, the aims are not learning outcomes. Both these points require a little unpacking. Regarding constructivism, a warning note should be sounded about this educational approach. Much has been written about it, and there are many variants of it (Petraglia, 1998), so it would be useful if I outlined four traits of a constructivist learning environment that are used in the PI negotiation project. First, the basis for the project is what might be termed an authentic problem (Jonassen 1999; 2001; Schank et al 1999). The term 'authentic' is problematic, but I take it to refer to a problem-based situation that, as much as can be within a simulation environment, approaches the complexity of actual professional practice. This leads us to the second trait, namely that the problem is suitably open or ill-structured, so that students require to construct the nature of the problem before they begin to reach for options or solutions. Third, the problem is embedded in a context of social negotiation, where there is both differentiated learning (ie where individuals complete tasks) and 
collaborative learning (Flower 1996; Lai-Chong \& Wong 1995; Lunenberg 1998; Lave \& Wenger 1991; Vygotsky 1978). Fourth (and as a result of the previous traits), the online learning environment is designed to enable students to construct knowledge, both substantive knowledge of law and procedural knowledge of legal transactions. In this sense, the project can be said to be an example of 'transactional learning' (Brown 2000; Brown, Collins \& Duguid 1989; Schon 1987)

Before we examine the project in more detail it might be useful to describe at this point what activities students perform that are constructivist in nature. One of the first is that they require to construct the client problem before they can begin to build a negotiation strategy; and this leads them into fact-finding (what's the background of our client? Which injuries? How extensive? Any long-term implications? Any witnesses? What do they say? How persuasive are they?) and legal research (liability, possible third party liability, contributory negligence, quantum, damages, solatium, etc). In so doing, they begin to construct the gestalt of client representation in a case. Although they are given an outline of a typical PI transaction, to a high degree they construct their own case. They thus regulate their learning, and monitor it. As Pintrich and De Groot point out (1990), the process of looking ahead and review of evidence (what they call 'orientation') is an important part of self-regulation or metacognition; and this too is an essential component of constructivist learning.

The second main point regarding the aims of the project, namely that they are not learning outcomes in the normally accepted meaning of this phrase, also requires more explanation. Statements of learning outcomes are now the accepted way of communicating to students what they should aim to do in an educational activity. However the PI project aims do not do this. Rather, what they do is to set standards, in shorthand, for the types and quality of communications we expect that students will produce in the project. A number of educationalists have pointed out the dangers of using learning outcomes, particularly in skills-based initiatives. Lawrence Stenhouse, a noted curriculum designer and theorist, for example, outlined the case against learning outcomes quite convincingly, and most of his argument can be summarised as follows:

- being general, they gave little guidance in planning interventions

- objectives tend to become 'ad hoc substitutes for hypotheses'

- they give the illusion of predicting what ought to happen

- they imply the idea of 'teacher-proofing' the curriculum, thus losing the value of 'divergent interpretations'

- they stop students having their own objectives

- they inhibit speculation

- they have unexpected consequences for schools as institutions as well as teacher practice ${ }^{2}$ (Stenhouse, 1983, 81-2)

\footnotetext{
${ }^{2}$ It is interesting to note that on this last point, Stenhouse was in complete agreement with Alasdair MacIntyre's statement in After Virtue that

$[p]$ ractices must not be confused with institutions. Chess, physics and medicine are practices; chess clubs, laboratories, universities and hospitals are institutions. Institutions are characteristically and necessarily concerned with what I have called external goods. They are involved in acquiring money and other material goods; they are structured in terms of power and status, and they distribute money, power and status as rewards.

As a result of this tension, MacIntyre observes wryly, 'the ideals and the creativity of the practice are always vulnerable to the acquisitiveness of the institution, in which the co-operative care for the common goods of the practice is always vulnerable to the competitiveness of the institution.' As a result, MacIntyre comments, 'without justice, courage and truthfulness, practices could not resist the corrupting power of institutions' (MacIntyre, p.181). It is a remarkable passage, and one entirely applicable to legal education. The role that web-based teaching and learning, as well as more established practices such as the aims \& objectives movement, semesterisation, and many other institutional practices, require to be critically examined in their effects on legal educational practice.
} 
These points have been echoed and elaborated by others in the field of legal education. Stuart Toddington, writing from a jurisprudential angle, commented that

The problem [...] is that the narrow conception of skills employed [in LPCtype literature] is now the dominant conception and that this dominance is becoming more entrenched. Thus the space for imaginative discourse becomes smaller as the habitual usages, associations and references of the managerial/clerical perspective become more difficult to penetrate. (Toddington 1996, 69)

Part of the 'narrow conception of skills' is precisely the mechanistic statement of outcomes that lays down what students are supposed to do. Really, what students themselves need to do, and what constructivists tell us they are best to do, is to find their own voice and performative skills so that they can best carry out the general task of negotiation, interviewing, and so forth.

\section{Resources and administration}

The PI Negotiation Project centres around an employee who is injured during the course of his employment. He wants to claim compensation against his employer for his injuries. For several years the project was run purely on email clients. The environment was highly constrained but communication and negotiation was possible. Students received information by sending emails to an anonymous address, and then used this information to work out negotiation strategy. As a strategy game and communication platform, the project generally worked well; but it bore little resemblance to the realities of PI legal practice.

In the first web-based version, we used Cold Fusion to create restricted web pages for each firm (48 in all). Documents in a database were sent to a firm's web page when it requested them; and it was possible to send individual text messages, too. The virtual community was restricted to addresses at the top of emails. This was a more realistic environment, and for the first time it was possible to derive statistics about the patterns of student communication as well as assessing the quality of communications. However there were still many constraints on the types of communication possible, and little verisimilitude to legal practice.

The second web-based iteration employed the ability of the web to disguise character, and to deliver graphics as well as text. We increased the number of information sources (and, correspondingly, the number of e-teaching assistants to service the sources), added graphics, a map, and much more information

The texts, contexts, characters, and information that surround the relatively simple and unremarkable case was administered in the following ways for pedagogical reasons:

1. the student body of 180 students was divided into firms of 4 , making a total of 46 firms. 23 acted for the claimant, while the other 23 were the insurer's solicitors. 46 sets of documentation were constructed, based largely on templates, but with important details altered to prevent plagiarism across cases.

2. Each firm had a passworded virtual office consisting of a web page in Outlook, access to FAQs describing this and other online projects, discussion forums and other resources. Students contacted information sources, each other and their opposite sides via email and attachments. Below is a screen shot of a typical student firm front page: 


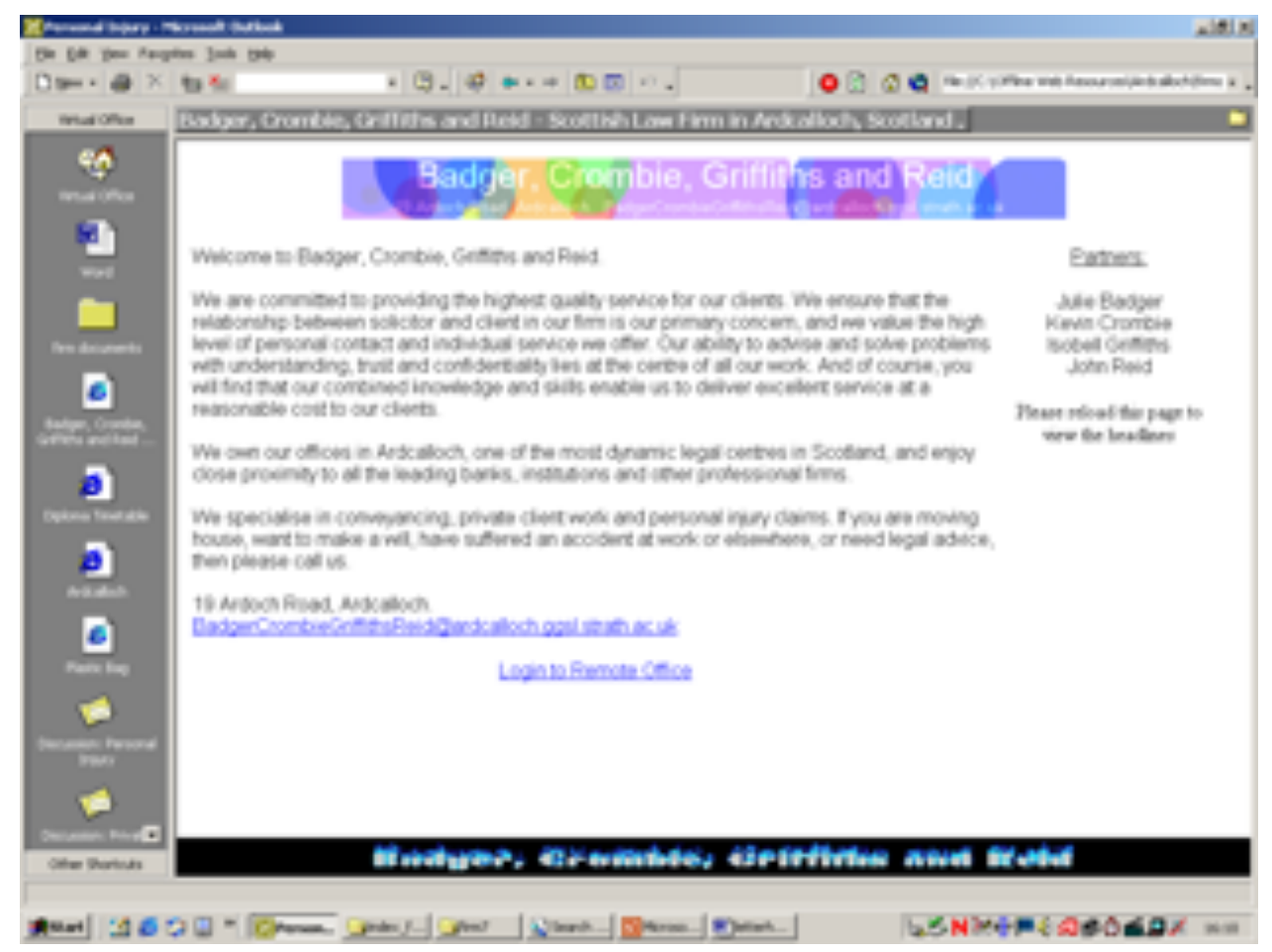

Figure 1

Students were given the facility to customise the text and the banner headline of their pages, as well as the headers and footers in their correspondence (this was given as a drafting activity early in the year). As a result, many of them reported in feedback that they felt a greater sense of ownership and participation in the firm. This is borne out by research into participatory design (Schneiderman, 1998).

3. three anonymous information sources (myself and two postgraduate teaching assistants) supplied students with the information that they required in order to take the case forward. When answering firms' emails we would always answer in character, so that the email appeared to originate from the addressee in the student email. Where a student wanted to contact a character not listed in the virtual community (see below), they simply contacted a post restante address.

4. the start of the case was the appearance in the claimant agents' Inboxes of a precognition or statement; and in the insurers' soliciters' Inboxes of an extract from the welding company's Accident Book describing the incident.

5. the firms were given 11 weeks to achieve settlement. Litigation was not an option open to them.

6. students were given an introductory lecture at the start of the project by the author and a practitioner in PI transactions; and at the end of the project the yeargroup was given a general feedback lecture. Feedback was also given at time via the discussion forum, and by the anonymous information sources that would be acting in character. For example, if a letter to a client was unjustifiably legalistic, the 'client' (ie one of the teaching assistants or myself) had been told to respond in character.

7. a virtual community. This is in many respects the heart of the project, and is described in detail in the next section. 


\section{The virtual community}

This consists of a fictional town, situated on the south bank of the Clyde Ardcalloch. The town has a history stretching back to the seventh century, a number of districts, including suburbs, business and industrial estates, and a town centre. It has businesses, a newspaper, a town council, Sheriff Court, and legal institutions such as a local Faculty of Procurators. In reality it exists as a complex of software, web sites and email routings. Like real towns, it is constantly undergoing repair, renovation, rebuilding; and the map is now in its fourth iteration. Below are screen shots of the third iteration, used in last year's PI project.

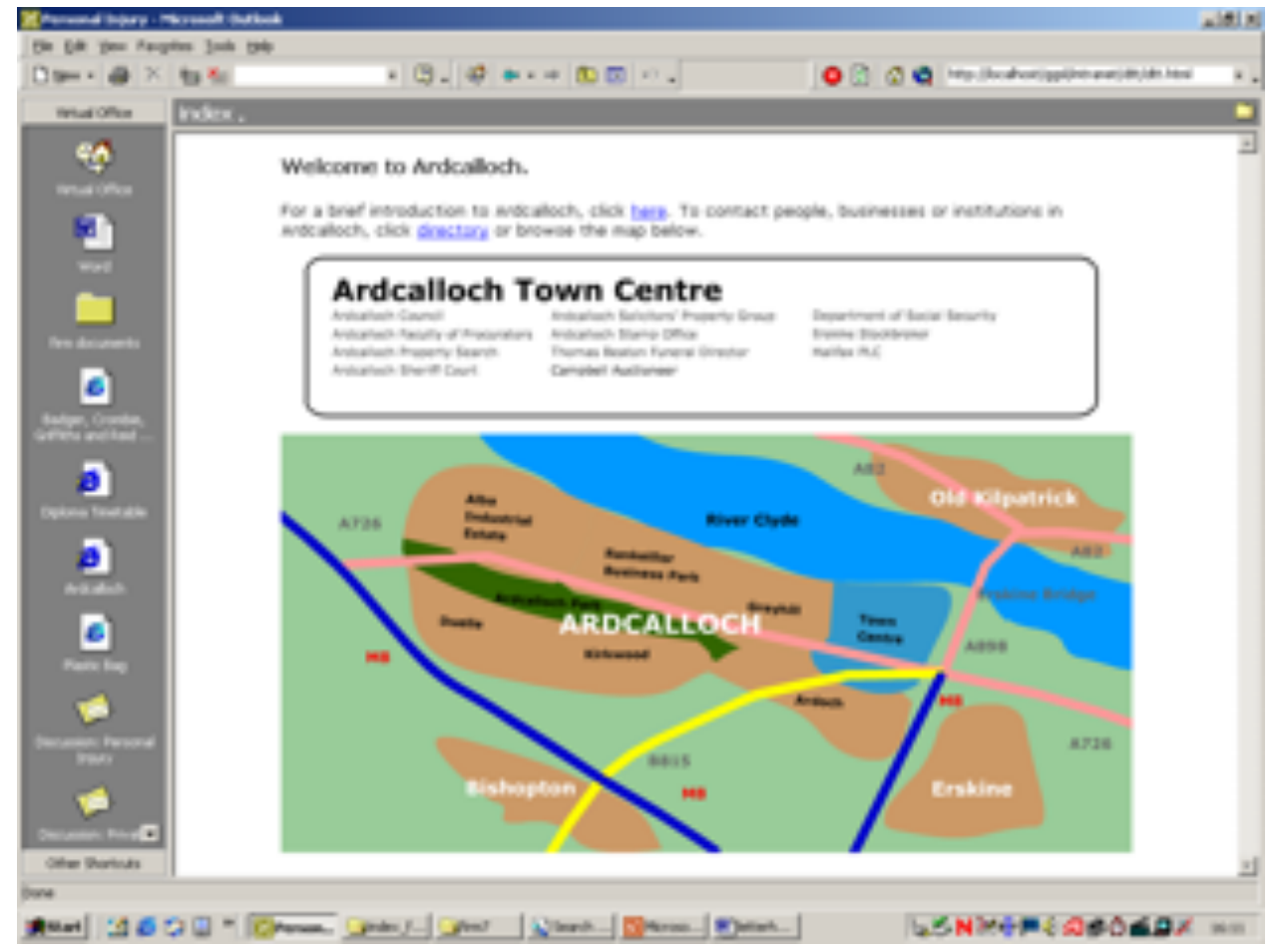

Figure 2 


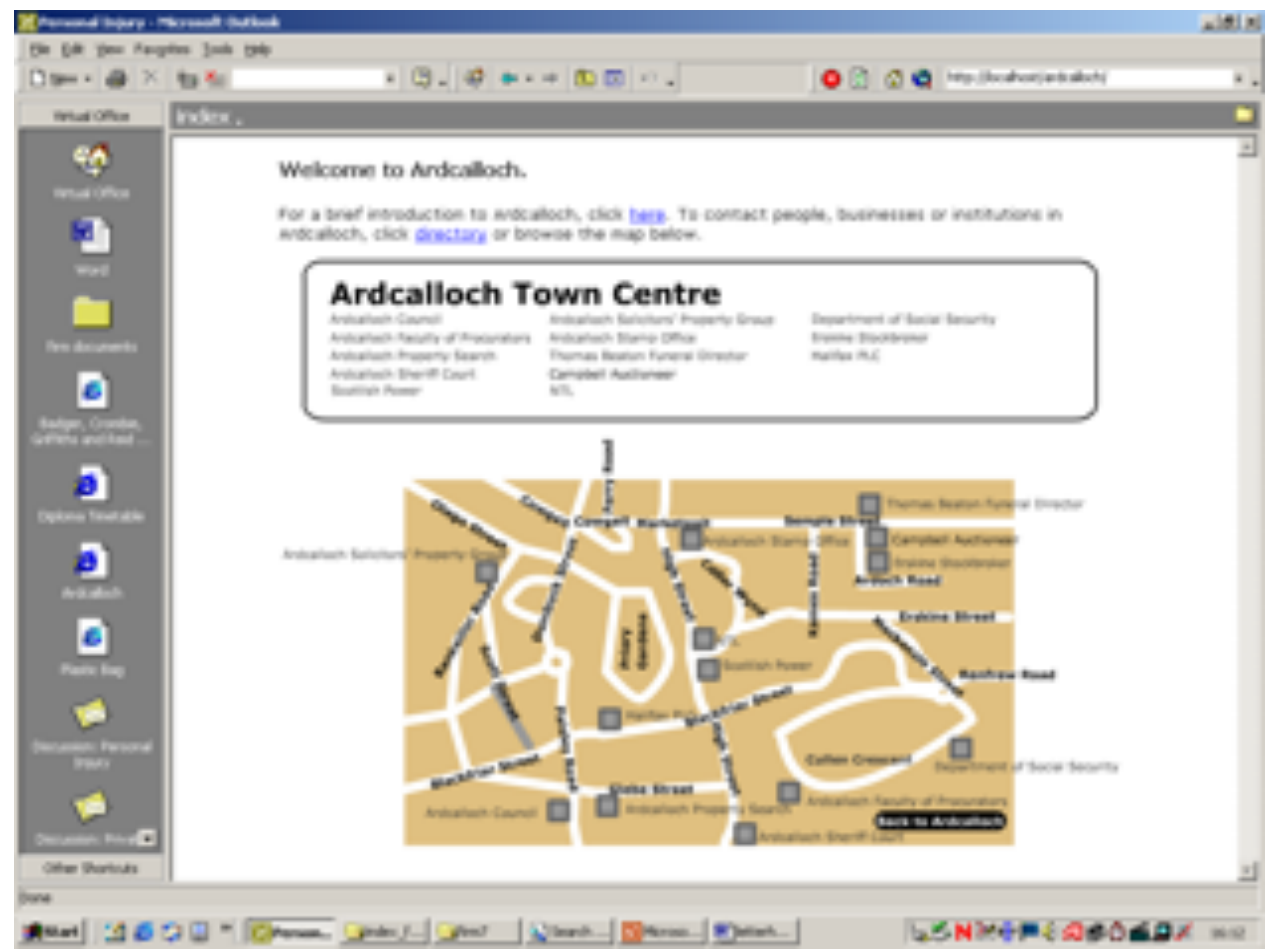

\section{Figure 3}

Figure 2 shows the overview of Ardcalloch in its broader topographical setting (districts turn blue on mouse roll-over), while Figure 3 shows the detail of the town centre. The whole community consists of two gigabytes of information (including graphics, texts, scripts) - presently around 17,000 files. Below is an example of a website used in transactions and projects - Campbell's Auctioneers. (figure 4). Figure 5 below shows the start of the history narrative for the town. The narrative is used to present students with a series of counter-factuals - a series of 'what-ifs' in Scottish history and culture, and centred largely on legal activities. The narrative can thus be used for legal historical, as well as jurisprudential purposes. 


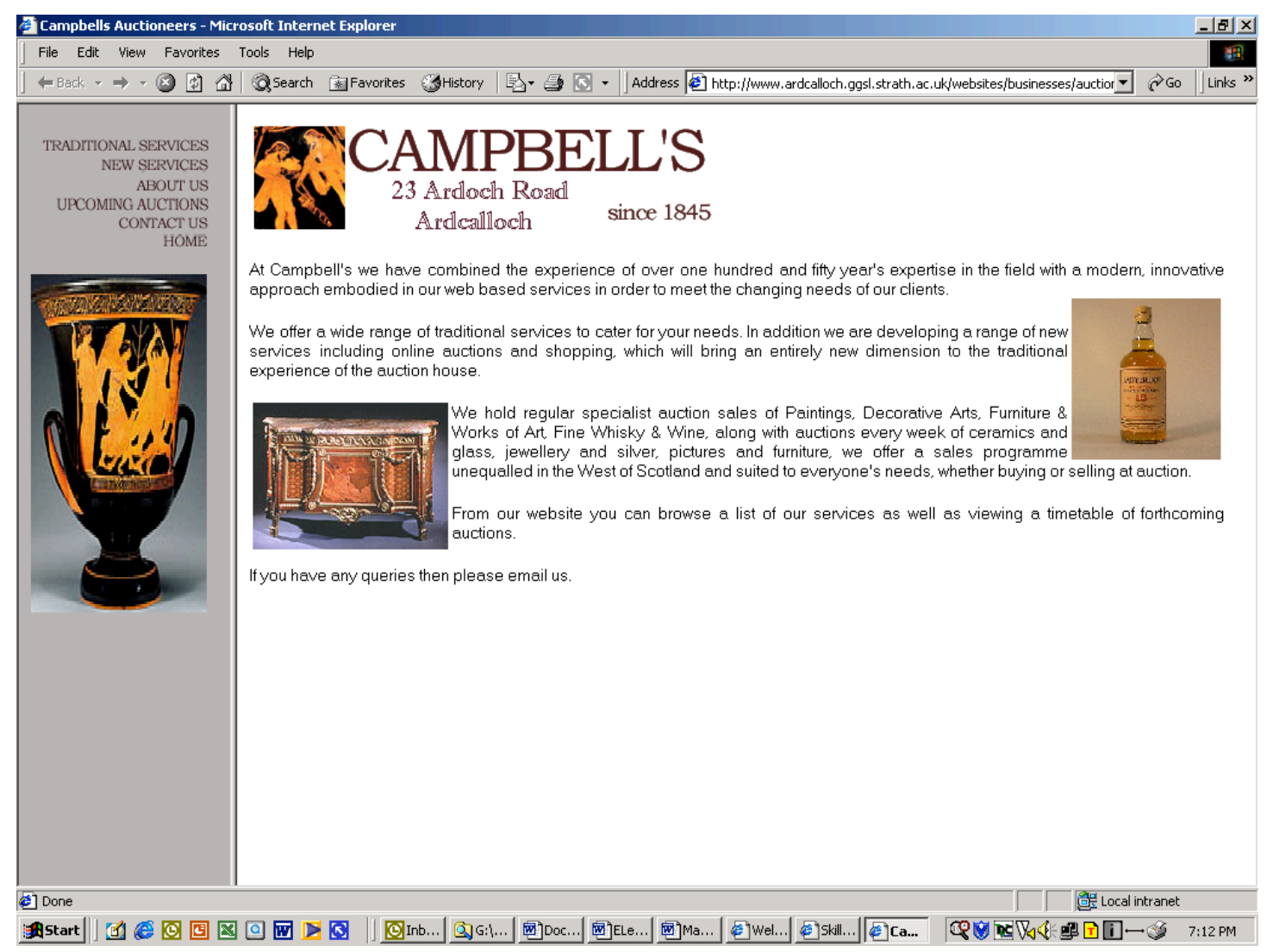

\section{Figure 4}

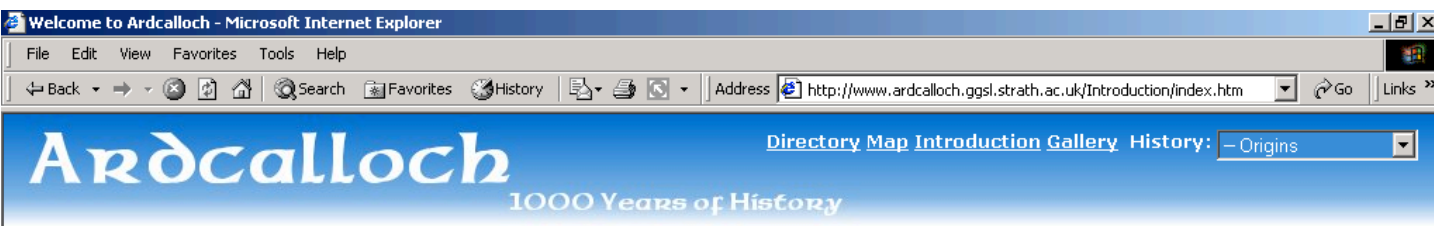

\section{Origins}

The name of the town is Celtic in origin. 'Cailleach' means 'old women' or cowled women', possibly referring to nuns. There is a legend that the priory of St Cerulus was built on the site of an earlier Celtic foundation attributed to St Kentigerna the daughter of Cellach. Prince of Leinster (early eighth century, d. 733). The island of Inchcailleach in Loch Lomond, where she died, is apparently derived from the same root According to Bede, a chapel, dedicated to her, and containing some of her bones, was erected some time in the tenth century. No trace of this has been found, though it is probable that the Premonstratensian foundation of St Michael in the fourteenth century was built upon the site of this early chapel. Bede's account is corroborated by the Onkneyinga Sag which relates that Earl Rognvald, great-nephew of Saint Magnus and builder of the foundations of St Magnus cathedral, on his crusade to the Holy Land, visited her shrine around 1132 to pray for his safe deliverance. St Kentigerna must have listened to the Earl, for he returned to Orkney two years later, after a remarkable series of adventures.

There is also evidence that Ardcalloch was originally a settlement which grew up around the Clyde crossing at this point in the river, which is the lowest crossing point for the major settlement on Dunbarton Rock, on the other side of the river. It would appear that in early medieval times it was possible to walk across the river at this point at low tide. There were local stories that marker poles were driven into the mud for this purpose; and indeed there are records made by James Watt that bear this out. During the work he carried out in preparation for his report on the river in the later eighteenth century, he recorded that 'there are the remaines of wooden stakes driven deep into the mud of the river, from one side to the other as if put there for the purpose of guiding travellers across the river, else for the siting of fishing nets'.

Watt's deduction was given corroboration in 1885 when workmen excavating a railway spur to the docks came upon a roadway of neatly laid stones, indicating a causeway that led down to the old ford. Local historians surmised that it was the Roman road to Dumbarton, and later archaeology has confirmed that this was indeed the direction of the road.

During the 1750 s workmen repairing the roadway at the crossing point unearthed a hull composed of planks pegged to a wooden frame and set in a keel. From contemporary accounts it would appear that the vessel was constructed using viking techniques. The vessel was preserved in a house turned into a museum of the Clyde, which was later demolished by a bomb in World War II.

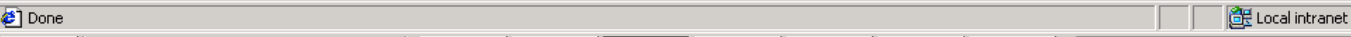

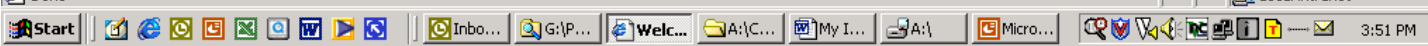

\section{Figure 5}


The town represents a unique repository of information not only for the PI project but for other projects, too, on the Diploma. For example, students practise conveyancing by buying or selling houses with actual title sheets - real properties that are given false addresses in the town's suburbs. The whole conveyancing transaction is carried out online: students liaise with Registers of Scotland on electronic registration of title. In this, students are perhaps three or four years ahead of what will become real practice in conveyancing in Scotland.

The town, therefore, represents a simulation of reality for the purposes of learning. Students can carry out legal procedures within a safe environment, while knowing that many of them will be carrying out identical or similar procedures when they start their traineeships in around six months' time. In this sense, the town enables situated and transactional learning. It does so within an information-rich environment that can accommodate fairly constrained legal transactions (ie those that have what one might regard as a reasonably linear structure) or more open-field transactions such as the PI project. The town, though, is not limited to legal transactions. It could be used over the range of many undergraduate courses and in other disciplines to provide the essential architecture for transactional learning- in, business, cultural studies, built environment, and so on.

\section{Statistics}

For the last two years we have collected statistics on the running of the PI project, including all communications sent by all firms, by each side in the transaction, and the type of communications sent. A full statistical analysis of the data would stretch beyond the word limits of this article, but there are two significant issues that we can focus on in relation to the themes of this article and journal, namely the roles played by social communication and time management.

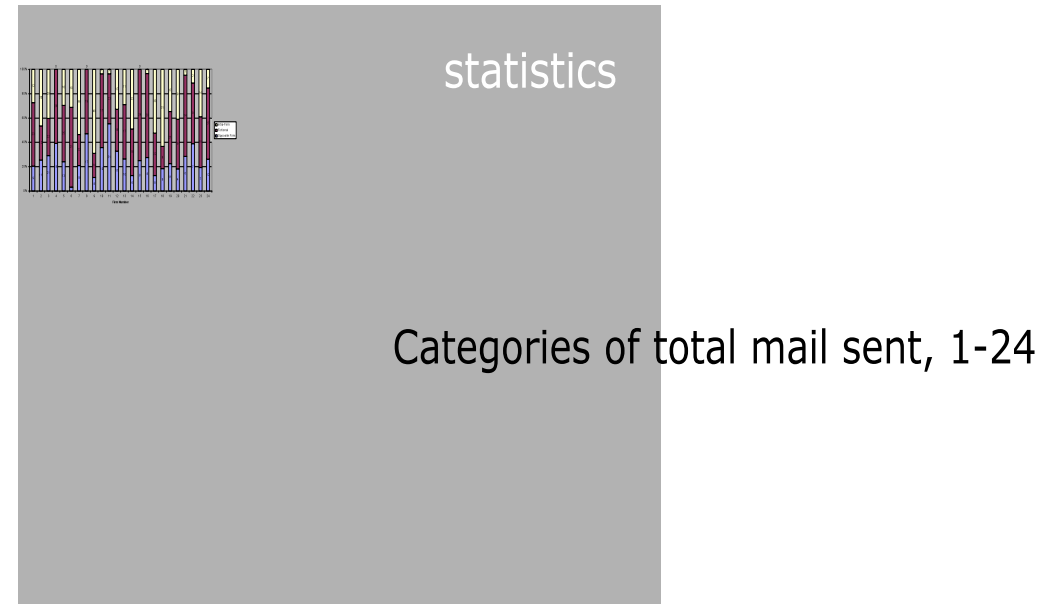

\section{Figure 6}


Figure 6 shows the three different categories of emails sent in the project by firms 1-24 (firm 1 was matched against 2, 3 against 4, and so on; while the odd numbers were always acting for the claimant). The light-coloured section of each column represents the mail sent by students intra-firm; the middle section represents communications with the fictional in Ardcalloch, while the lower sections represent communications with the other side. The middle section is the most consistent, reflecting the factual research done by firms in Ardcalloch - a range from 9 to twenty-eight emails. The other two types of communications reveal interesting patterns. Intra-firm emails ranged from zero to 49 . It was clear from the emails that those who had sent each other many were not only talking about the project, but using email for social purposes too. It is difficult to make a direct correlation here, but it was significant that those firms who were in social communication with each other drew up the more sophisticated negotiation strategies. Of course, it could be said that those firms who were not communicating online were talking offline, in the coffee bar or at lectures. This is undeniable; but the two factors of social bonding in the firm environment and use of email to commit members of the firm to a plan seemed to aid the development of negotiation strategy.

In the inter-firm communication, most firms were evenly matched and replied formally to each other. Where numbers are not matched, the firm sent supplementary communications that backed up evidence, or made further claims or counter-claims. Firm 5 sent a considerably body of mail to firm 6 before the latter answered, seeking a face-to-face meeting - hence the lack of communication on their part.

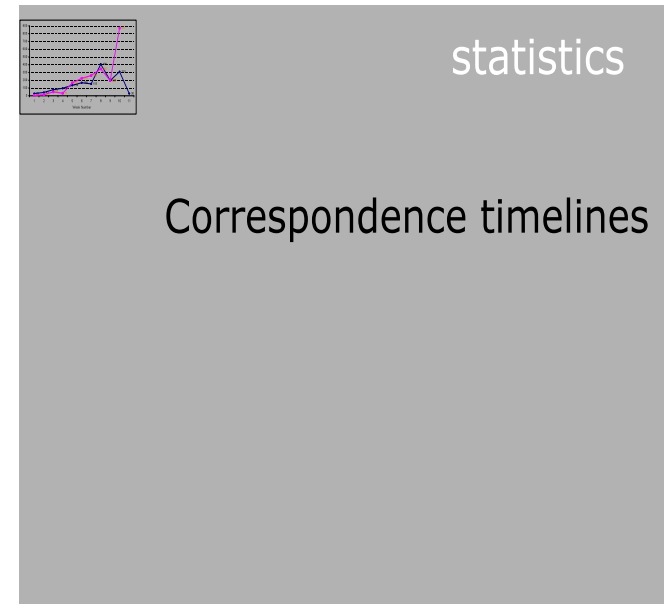

\section{Figure 6}

Figure 6 shows the timeline of the communications. The lighter colour refers to session 99/00, while the darker represents 00/01. Note the huge spike in communicative activity in weeks 9-11 in session 99/00 - the result of poor time management. Answering this volume of email in such a short space of time proved difficult for the two teaching assistants and myself. In the introductory lecture to the project in session 00/01 this result was shown to students, and 
they were asked to manage the project more effectively. The result was a remarkable rise in activity throughout the length of the project, and a corresponding decrease in activity towards the end of the project. This graph has proved to be an effective time management feedback tool for students.

\section{Feedback: who learned what...}

What students learn is very often not what we think they are learning. In some respects the open texture of constructivist learning encourages students to learn divergently, and according to their own needs and agenda. This was evident in the feedback we received in the reflect reports. Some of this is extracted below:

This project was an excellent exercise in teamwork. Our team seemed to work well together which did make a difference. The project forced us to think logically and made us put the law into practice.

$[\ldots]$

We were unsure how to deal with the question of medical consultant's fees, given that we did not realise at first that there would be a fee and therefore did not seek the permission of the client to obtain a medical report and did not inform him in advance that he would be liable to pay the fee. When subsequently told by our client that he could not afford to pay a consultant's fee, we had to take responsibility for the fees ourselves until insurance paid for it. This was one of the questions that we posed to the discussion forum, as we were initially unsure how to deal with the situation.

I felt that one of the things we could have improved on was the checking of our correspondence before sending. On at least two occasions we had to send letters apologising for previous inaccuracies, or for mistakes in whom we had sent letter to. In practice this would suggest a lack of professionalism, and would be unforgivable. It also led to inefficiency in the long run, wasting time on extra letters.

Moreover, if we had thought a little harder we could have minimised the number of letters we sent, by requesting all relevant information form a person in one go, rather than having to continually request further details. This was particularly true of our correspondence with Mr Graham, and in real life I suspect that a client would get a bit impatient if he were constantly harassed for more evidence. I did feel that we all lacked a little bit of experience in such matters; knowing what to ask for and from whom, and I am confident that this exercise has helped us in that regard.

Finally I would say that I allowed my personal organisation to slip as the project went on, and my filing system went a little awry. This then led to further difficulties, such as in the compiling of this report, as many of the hard copies of letters that we had all been given were out of order. A saving grace was that, as a group, we had compiled a collective file, meant to mimic a proper law firm's file, which contained a copy of all minutes of meetings, correspondence, memos, e-mails etc. That was an excellent idea. 
I found the whole experience to be extremely worthwhile. I believe it was a close as students will get to experiencing the 'real thing' before we commence our traineeships. It certainly taught us the importance of fact gathering before jumping in and trying to find a solution.

[...] Next time I would like to have a negotiation meeting. We took a decision as a firm not to have one mainly because we did not think that we would achieve much from it. Instead, we conducted the whole negotiation by letter. This undoubtedly had the advantage of letting both sides digest the contents of the letters at their own pace and responding accordingly. However, with hindsight, I think I would have enjoyed the experience of having to be fully prepared in advance of the negotiation meeting for anything which the other side produced.

The negotiation project certainly helped focus attention on letter writing skills and general IT skills. There were functions such as not to file and attachments to emails that I was not familiar with at the beginning of the project, but now using them is second nature. Furthermore, most projects/essays in the undergraduate degree have concentrated on testing your legal research skills; the negotiation project was probably the first assignment that I have done that has highlighted the importance of fact gathering. Finally the negotiation project gave you the opportunity to participate in the whole transaction from start to finish and take pride in the final settlement that you helped to achieve.

$[\ldots]$

Although at the beginning of the project I was dubious as to its worth, I can now understand why it is done and feel that it is probably the most practical thing we have done on the Diploma.

While establishing the facts was important, there was an additional challenge in this exercise that was both useful and amusing. It very quickly became apparent that this was an exercise in plain English. [...] I enjoyed trying to frame questions [to the client] so that both the tone and the content would be more likely to evince a response. This was largely successful with only one rebuff for 'legalese', but in the same letter we got gossip about extra-marital exploits!

Despite the difficulties with the firm I have enjoyed the project. I am optimistic that the sessions with VG [counsellor] will be an invaluable experience to us all. Even without this, simply going through the process of recognising the difficulty and deciding to seek assistance has been personally challenging and illuminating. I have had to examine my part in the group process in order to be open to learning better ways of dealing with issues. I feel I have benefited personally and professionally. This has not been an easy experience but real learning seldom is. It poses a threat to existing ideas and ways of operating. An essential element in the learning process is being open to having one's ideas and views challenged and this cannot be achieved without risk.

In their reports students commented that they learned about the following issues:

- extended team working 
- fact-finding - how much, when, from whom

- case-based research

- process thinking

- setting out negotiation strategies in the context of relatively uncertain information

- writing to specific audiences

- structuring the argument of a case from start to finish

- keeping cool in face-to-face negotiations

A number of them recognised the need for more effective delegation, while others realised the value of notes to file and well-structured directories on their website.

Every year we learn from the process of running this project about the nature of online project work, simulations, and much else. For example, this was the first year that we allowed students to structure their work folders - we realise now that more needs to be done to discuss with students how legal office directory structures need to be managed. Students were given IT training, but commented that they needed more: as one student put it, misquoting Star Trek, 'this is IT, but not as we've known it'.

Students also wanted more video resources: a video walk-through of the premises where the accident occurred, and a video precognition or interview with the client. The former is more difficult to arrange, but we have already filmed the latter, using a combination of video and voice-over (to state the variables of the 23 different cases). This resource will help to link the project to other, more cognitivist approaches to skills-based learning, eg client interviewing and letter writing.

Sometimes student feedback leads us to think about how we structure information in the project. A good example of this is the feedback that some students gave regarding the structure of the transaction: they wanted the case to be more structured for them. Since one of the points of this activity is to replicate the uncertain nature of real cases, we will not do this; and in any case we gave students an outline structure of a typical transaction in the form of a handout in the introductory lecture. Nevertheless the students' felt needs remained - at least 15 of them asked for this. It is probably the case that, given the length of the project and its electronic environment, students forgot about the paper handout. Next year we will supply the handout under the resources heading on their web pages alongside the FAQ and discussion forums so that it is easily to hand and can be consulted when appropriate.

Some students complained that others in their firms were not coming to meetings, or were not producing work on time, or that their work was below expectations. While we had a procedure for this that involved a person-centred counsellor, it was clear to us that there needed to be a greater sense of authority within the firm. Next year, a tutor will take the role of a 'managing partner' in each firm. The tutor will meet once a month and will ensure equitable work loads, and proper sharing of results so that peer learning can take place. A student will be appointed in each firm as 'case manager' for each of the projects, to ensure that case deadlines are managed. Students will also use electronic logbooks to reflect on the process of the projects, and these will be based on the form of logbooks that will be supplied by the Law Society for use in their traineeships. 


\section{Conclusions}

There are many conclusions one can draw from a web-based project of this size and complexity; but one of the fundamental ones is the extent to which theory can help us to determine best practice. When one reads the literature of instructional design, one of the overall impressions is of a science of computerbased instruction, where users are taught according to a transmission model of education (Merrill 1992; 1998; 1999). But one of the key aims of the Diploma is to integrate skills and knowledge, and to enable students to practise such integrative performance across a range of subject domains in law. Constructivism, with its emphasis on the social construction of knowledge, and negotiation of knowledge within problem-based environments, is ideally suited to this aim, and indeed to many web-based learning initiatives. Such initiatives, I would argue, can help us to move from a myopic focus on what West, cited above, termed 'mechanical formalities, on systems of accreditation and assessment' to 'the poetics of learning and creativity'.

The difficulties in creating such an environment should not be underestimated. We encountered major administrative problems, training, both for students and project information sources, was essential; and we found the process of constructing the materials painfully slow at times (we are currently streamlining this last aspect of the project's construction). The 'we', the actors of this paper consists of myself, the Computer Officer of the GGSL, Scott Walker, and a number of student programmers. We are a close-knit group and our flexibility has contributed to the flexibility and on-going development of the environment, for example in rapid prototyping. As Gartner and Wagner (1996) have pointed out,

An evolving design acts as an intermediary in the sense that the participating human actors inscribe their aims, problem definitions, and design ideas in the system and that these inscriptions in turn mediate the social relations within the network. (pp.190-191)

It is not too much to claim that such inscription is a form of educational artistry. First and foremost, though, it is a learning environment, one that is highly effective in its context, and transferable to different areas of law.

\section{References}

Brown, J.S. (2000), Growing up digital: How the web changes work, education, and the ways people learn. Change, 32, 2, 10-20

Dickinson, D. (1995) Multimedia Myths, Australian Personal Computer, 16, 10, 140-51

Gartner, J., \& Wagner, I., (1996). Mapping actors and agendas: Political frameworks of systems design and participation, Human-Computer Interaction, $11,3,187-214$.

Hiltz, S.R., Coppola, N., Rotter, N., Turoff, M., Benbunan-Fich, R. (2000) Measuring the importance of collaborative learning for the effectiveness of ALN: a multi-measure, multi-method approach. Journal of Asynchronous Learning Networks, 4, 2, September, http://www.aln.org/alnweb/journal/Vol4 issue2/le/Hiltz/le-hiltz.htm

Jonassen, D.H., (1999), Designing constructivist learning environments. In Reigeluth, C.M. (ed), Instructional Design Theories and Models: A New Paradigm of Instructional Technology, vol II. Lawrence Erlbaum Associates, Mahwah, NJ 
Jonnassen, D.H., (2001), Design of constructivist learning environments, http://www.coe.missouri.edu/\%7Ejonassen/courses/CLE/index.html

Lai-Chong, L., and Wong, K. (1995), Implications and problems of constructivism for instructional design. Educational Review (Hong Kong), 23, 73-104

Laurillard, D. 1993 Rethinking University Teaching: A Framework for the Effective Use of Educational Technology. Routledge, London

Lave, J., \& Wenger, E. (1991), Situated Learning: Legitimate Peripheral Participation, Cambridge University Press, New York

Lunenberg, F.C., (1998) Constructivism and technology: instructional designs for successful education reform. Journal of Instructional Psychology, 25, 75-82

MacIntyre, A. (1981) After Virtue: A Study in Moral Theory, Duckworth, London

Merrill, M.D., (1992), Constructivism and instructional design. In Duffy, T.M. and Jonassen, D. (eds), Constructivism and the Technology of Instruction, Lawrence Erlbaum Associates, Hillsdale, NJ

Merrill, M.D., (1998), ID expert: A second generation instructional development system, Instructional Sciences, 26, 3-4, 243-62

Merrill, M.D., (1999), Instructional transaction theory. In Reigeluth, C.M. (ed), Instructional Design Theories and Models: A New Paradigm of Instructional Technology, vol II. Lawrence Erlbaum Associates, Mahwah, NJ

Pintrich, P.R., and De Groot, E.V. (1990) Motivational and self-regulated learning components of class-room academic performance, Journal of Educational Psychology, 82, 33-40

Schank, R.C., Berman, T.R., MacPherson, K.A. (1999), Learning by doing. In Reigeluth, C.M. (ed), Instructional Design Theories and Models: A New Paradigm of Instructional Technology, vol II. Lawrence Erlbaum Associates, Mahwah, NJ

Schön, D., (1987) Educating the Reflective Practitioner: Toward a New Design for Teaching and Learning in the Professions, Jossey-Bass, San Francisco

Shneiderman, B., (1998). Designing the User Interface.(3rd ed.), Addison Wesley, Reading, Mass.

Stenhouse, L. (1983), Authority, Education and Emancipation, Heinemann, London

Toddington, S. The emperor's new skills: The academy, the profession and the idea of legal education. In P.B.H. Birks, editor, (1996) What are Law Schools for? Pressing Problems in the Law, vol 2, Oxford University Press, Oxford

Turkle, S. (1997) Growing up in the culture of simulation. In Beyond Calculation: The Next Fifty Years of Computing edited by Denning, P.J. and Metcalfe, R. M., Copernicus, New York

Vygotsky, L.S. (1978), Mind in Society: The Development of Higher Psychological Processes, Harvard University Press, Cambridge, MA 
West, L. (1996), Beyond Fragments. Adults, Motivation and Higher Education: A Biographical Analysis, Taylor \& Francis, London, 1996 